\title{
Editorial
}

\section{The Millennial Generation of Thrombosis and Hemostasis}

\author{
Stefano Barco ${ }^{1,2}$ \\ ${ }^{1}$ Center for Thrombosis and Hemostasis, University Medical Center \\ Mainz, Johannes Gutenberg University, Mainz, Germany \\ ${ }^{2}$ Clinic of Angiology, University Hospital Zurich, Zurich, Switzerland
}

Hämostaseologie 2020;40:259-263.

A new generation of scientists and physicians born in the 1980s and 1990s is rising, more than 60 years after establishing the Deutsche Arbeitsgemeinschaft für Blutgerinnungsforschung (DAB), today the Gesellschaft für Thrombose- und Hämostaseforschung (GTH), and 40 years after the first issue of Hämostaseologie-Progress in Haemostasis. ${ }^{1,2}$ Their careers unfold at a time when structured learning programs are being created, the interest in thrombosis and hemostasis expands, and networking opportunities reach their highest potential. This period also coincides with the achievement, at least to a large part, of previously unreachable goals, such as a decrease in mortality related to severe disorders of coagulation, notably pulmonary embolism ${ }^{3}$ and hemophilia. ${ }^{4}$ In the years to come, the millennial generation of thrombosis and hemostasis experts will shape scientific societies, improve evidence for clinical care, and increase public awareness with the commitment of representing a positive clustering force.

This special issue of Hämostaseologie-Progress in Haemostasis hosts 10 narrative reviews authored by 29 young experts - in a well-balanced sex ratio - of the upcoming generation of leaders in the field. Although as many as 13 countries and 23 institutions are represented, this issue by no means presumes to (and cannot) be exhaustive. Instead, its objective is to give a snapshot of global positions and interests, ranging across several clinical conditions and research targets.

As a highly interdisciplinary field in medicine, thrombosis and hemostasis necessarily demands the active interaction of a broad spectrum of clinicians and scientists. Thus, it is not really unexpected that the authors identified themselves as internists, hematologists, intensive care physicians, cardiologists, pulmonologists, hemostasis experts, angiologists, biochemists, biologists, and biostatisticians.

The structure of these articles aims to provide the readers with a comprehensive overview of specific topics, to discuss unmet needs, and to present novel research activities that may dramatically change or even revolutionize the field in future years. The final paragraph of each review contains a section denominated time capsule. ${ }^{5}$ In this capsule, the authors had been asked to transmit messages, outline expectations, or make predictions regarding the reviewed topic. The receivers are the authors themselves in the year 2050 and the next generation of physicians and scientists in thrombosis and hemostasis.

In their article, Drs. van Es, Ay, and Jara-Palomares discuss different screening strategies and risk assessment models for occult cancer after (unprovoked) venous thromboembolism (VTE). ${ }^{6}$ Elegant solutions to solve this arcana may be around the corner.

Drs. Gautam, Sebastian, and Klok dissect the partially overlapping entities of chronic thrombosis, recurrent thrombosis, and postthrombotic syndrome, and elucidate clinical implications. The readers are virtually accompanied from the radiology department to patient bedside. ${ }^{7}$

Old age has taken on a new meaning in our societies and this has a major impact on the delivery of patient care and medical therapies. Drs. Giustozzi, Castellucci, and Barnes review available data on the efficacy and safety of anticoagulant treatment for atrial fibrillation and VTE in nonagenarians. ${ }^{8}$

The idea that some venous thromboses have an infectious origin is consistent with the observation that a thrombus may co-occur with local infection and inflammation. Drs. Valerio and Riva process and develop this key concept in their summa, and provide the readers with a detailed update of the available knowledge. ${ }^{9}$

In their review, Drs. Trinchero, Sholzberg, and Matino give an overview of the medical treatment of hemophilia $\mathrm{A}$ and B. A revolution in hemophilia treatment has occurred over the past 5 years and the authors discuss novel opportunities and challenges. ${ }^{10}$

Thrombotic thrombocytopenic purpura is a rare, potentially life-threatening disorder: Drs. Roose and Joly
Address for correspondence Stefano Barco, MD, PhD, FESC, Clinic for Angiology, University Hospital Zurich, Rämistrasse 100, RAE C 04, Zurich, 8091, Switzerland (e-mail: stefano.barco@usz.ch). (c) 2020 Georg Thieme Verlag KG Stuttgart · New York

received

May 12, 2020

accepted after revision

May 16, 2020
DOI https://doi.org/ 10.1055/a-1173-0662. ISSN 0720-9355. 
comprehensively summarize its pathophysiology and management, and identify a few solid pillars to sustain the development of curative treatments. ${ }^{11}$

Drs. Zaninetti, Sachs, and Palankar address the current available methods for biophysical investigations of platelets and the possible translation into the field of inherited platelet disorders, going into depth on biological and technical details. ${ }^{12}$

The pathophysiology of several forms of pulmonary hypertension remains to be fully clarified. The rationale of anticoagulant use in these patients and the available data are discussed by Drs. Bertoletti, Mismetti, and Giannakoulas. The authors did not forget to emphasize the potential risks related to the use of direct oral anticoagulants in this patient population. ${ }^{13}$

Drs. Skeith, Blondon, and Ní Áinle present the most recent evidence to better understand hemostatic mechanisms of preeclampsia, placenta-mediated pregnancy complications, and in women with thrombophilia. The review is conducted with the aid of a few illustrative clinical cases. ${ }^{14}$

Can we measure the individual prothrombotic or prohemorrhagic tendency by global coagulation assays? This question is answered by Drs. Reda, Morimont, Douxfils, and Ruihl, who foresee that these tests will play an important role in the future of laboratory diagnostics of hemostasis and thrombosis. $^{15}$

During the preparation of this special issue, we witnessed the coronavirus disease 2019 (COVID-19) outbreak. Most of us are being actively involved in patient care in parallel with research activities. Today, we know that COVID-19 is characterized by a substantial infectious rate and fatality, but it is still too early to speculate how the pandemic will evolve on a global scale. ${ }^{16}$ Apart from the predilection of the virus for epithelial cells, bilateral pneumonia causing an exaggerated inflammatory response, pulmonary-induced coagulopathy, and thromboembolic complications are integral features of the disease, at least in its most severe forms. ${ }^{17-20}$ Facing with such a global challenge, we, as young thrombosis and hemostasis experts, are called on duty to find innovative solutions.

As a junior Editorial Board member and current Guest Editor, I am very grateful to the Editor-in-Chief, Prof. Rüdiger Scharf, the authors, the Editorial Board members, and the referees for their invaluable input, which was instrumental to assemble and finalize this unique edition of Hämostaseologie-Progress in Haemostasis.

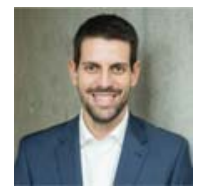

Stefano Barco, MD, PhD
Stefano Barco, MD, PhD, specialized in internal medicine at the University of Pavia and received a $\mathrm{PhD}$ in Vascular Medicine from the University of Amsterdam. He leads a research group at the Center for Thrombosis and Hemostasis of the University Medical Center Mainz and is staff physician at and responsible for the research unit of the Clinic of Angiology at the University Hospital Zurich.

Dr. Barco's research interests are in the management of venous thromboembolism with a focus on pulmonary embolism and special patient populations.
He is a Steering Committee and Data Safety Monitoring Board member of multinational trials in pulmonary embolism. Dr. Barco is an associate editor for Thrombosis Research and a junior Editorial Board member for HämostaseologieProgress in Haemostasis. He is member of the international Steering Committee of the World Thrombosis Day and Fellow of the European Society of Cardiology (FESC).

Acknowledgments

The work of Stefano Barco is supported by the German Federal Ministry of Education and Research (BMBF 01E01003 and 01E01503).

\section{References}

1 Scharf RE. 40 years of Hämostaseologie - progress in Haemostasis. Hamostaseologie 2020;40(01):7-8

2 Langer F, Renné T. 64th Annual Congress of the Gesellschaft für Thrombose- und Hämostaseforschung e.V. in Bremen. Hamostaseologie 2020;40(01):9-11

3 Barco S, Mahmoudpour SH, Valerio L, et al. Trends in mortality related to pulmonary embolism in the European Region, 200015: analysis of vital registration data from the WHO Mortality Database. Lancet Respir Med 2020;8(03):277-287

4 Payne AB, Ghaji N, Mehal JM, et al. Mortality trends and causes of death in persons with hemophilia in the United States, 1999-2014. Blood 2017; 130:755

5 Leizorovicz A, Cohen AT, Turpie AG, Olsson CG, Vaitkus PT, Goldhaber SZ; PREVENT Medical Thromboprophylaxis Study Group. Randomized, placebo-controlled trial of dalteparin for the prevention of venous thromboembolism in acutely ill medical patients. Circulation 2004;110(07):874-879

6 Van Es N, Ay C, Jara-Palomares L. Screening for occult cancer in patients with venous thromboembolism: past, present, and future. Hamostaseologie 2020;40(03):270-279

7 Gautam G, Sebastian T, Klok FA. How to differentiate recurrent deep vein thrombosis from post-thrombotic syndrome. Hamostaseologie 2020;40(03):280-290

8 Giustozzi M, Castellucci LA, Barnes GD. Management of anticoagulant treatment and anticoagulation-related complications in nonagenarians. Hamostaseologie 2020;40(03):292-300

9 Valerio L, Riva N. Head, neck and abdominopelvic septic thrombophlebitis: current evidence and challenges in diagnosis and treatment. Hamostaseologie 2020;40(03):301-310

10 Trinchero A, Sholzberg M, Matino D. The evolution of hemophilia care: clinical and laboratory advances, opportunities and challenges. Hamostaseologie 2020;40(03):311-321

11 Roose E, Joly BS. Current and future perspectives on ADAMTS13 and thrombotic thrombocytopenic purpura. Hamostaseologie 2020;40(03):322-336

12 Zaninetti C, Sachs L, Palankar R. Role of platelet cytoskeleton in platelet biomechanics: current and emerging methodologies and their potential relevance for the investigation of inherited platelet disorders. Hamostaseologie 2020;40(03):337-347

13 Bertoletti L, Mismetti V, Giannakoulas G. Use of anticoagulants in patients with pulmonary hypertension. Hamostaseologie 2020; 40(03):348-355

14 Skeith L, Blondon M, Ni Ainle F. Understanding and preventing placenta-mediated pregnancy complications. Hamostaseologie 2020;40(03):356-363

15 Reda S, Morimont L, Douxfils J, Rühl H. Can we measure the individual prothrombotic or prohemorrhagic tendency by global coagulation tests? Hamostaseologie 2020;40(03):364-378

16 Kirkcaldy RD, King BA, Brooks JT. COVID-19 and postinfection immunity: limited evidence, many remaining questions. JAMA 2020 
17 Klok FA, Kruip MJHA, van der Meer NJM, et al. Confirmation of the high cumulative incidence of thrombotic complications in critically ill ICU patients with COVID-19: An updated analysis. Thromb Res 2020 (e-pub ahead of print). Doi: 10.1016/j. thromres.2020.04.041

18 Lodigiani C, Iapichino G, Carenzo L, et al; Humanitas COVID-19 Task Force. Venous and arterial thromboembolic complications in
COVID-19 patients admitted to an academic hospital in Milan, Italy. Thromb Res 2020;191:9-14

19 Connors JM, Levy JH. COVID-19 and its implications for thrombosis and anticoagulation. Blood 2020 (e-pub ahead of print). Doi: 10.1182/blood.2020006000

20 Varga Z, Flammer AJ, Steiger P, et al. Endothelial cell infection and endotheliitis in COVID-19. Lancet 2020;395(10234):1417-1418 